\title{
OBSERVAÇÃO PARTICIPANTE: UMA ABORDAGEM METODOLÓGICA PARA A PSICOLOGIA ESCOLAR ${ }^{1}$
}

\author{
JOÃO BATISTA MARTINS ${ }^{2}$
}

\begin{abstract}
MARTINS, J.B. Observação participante: uma abordagem metodológica para a psicologia escolar. Semina: Ci. Sociais/Humanas, Londrina, v. 17, n. 3, p. 266-273, set. 1996.
\end{abstract}

RESUMO: O propósito deste trabalho é discutir a observação participante como uma metodologia apropriada para o trabalho do psicólogo escolar. Nós consideramos a escola como uma construção social circunscrita pelas representações sociais dos agentes que participam de seu dia a dia. A observação participante permite ao psicólogo pesquisar as estruturas das relações sociais e oferecer soluções alternativas para os problemas emergentes na realização das metas da escola. Portanto, o trabalho do psicólogo deve ser o de compreender as representações sociais dos segmentos sociais da escola no sentido de desvelar as contradições implícitas nas relações escolares rotineiras.

PALAVRAS-CHAVES: Psicologia escolar, observação participante, metodologia de pesquisa, cotidiano.

\section{LOCAI_IZANDO A ATUAÇÃO DO PSICÓLOGO ESCOLAR...}

A Psicologia, mais especificamente a nascida na segunda metade do Séc. XIX (Wundt, 1879), na Europa, numa sociedade capitalista industrial, desenvolveu-se através do embate de alguns paradigmas inconciliáveis (FIGUEIREDO, 1991, 1993). Possui, no entanto, uma unidade que, longe de ser científica, é ideológica. Constituiu-se como instrumento das necessidades da sociedade em que nasceu, com o objetivo de "selecionar, orientar, adaptar e racionalizar, visando, em última instância, a um aumento da produtividade". (PATTO, 1984, p. 87).

A Psicologia Escolar, por sua vez, na medida em que nasceu com as mãos dadas com a psicometria, desenvolveu um conjunto de atividades onde se destacam a avaliação da prontidão, organização de classes e diagnósticos e encaminhamentos de crianças com "distúrbios de aprendizagem".

No Brasil, a inserção dos psicólogos na área da educação foi fortemente influenciada por essas práticas e tèorias, impregnada pelas idéias do chamado "modelo clínico" (ANDALÓ, 1984), onde os problemas são equacionados em termos de saúde $x$ doença e eram interpretados como sintomas determinados por fatores subjacentes ao indivíduo. Neste modelo, em que o conceito de patologia é central, o papel do ambiente, embora considerado, é interpretado como secundário.
Uma das razões para o predomínio deste modelo pode ser vislumbrada com a implementação das concepções liberais subjacentes ao modelo capitalista desenvolvido nos países ocidentais, especialmente no terceiro mundo. Assim, uma concepção teórica como o modelo clínico, que deposita no indivíduo os principais determinantes dos "problemas psicológicos", encontrou ampla aceitação numa sociedade que tem no individualismo um de seus principais suportes ideológicos ("o sucesso ou o fracasso dependem basicamente do indivíduo").

A escola, por sua vez, reflete e reproduz as situações sociais que caracterizam tal modelo de sociedade. Assim, os mecanismos ideológicos inerentes ao sistema social - no Brasil extremamente marcado pelas desigualdades sociais - são naturalizados através de um processo de interiorização, que faz com que passem a fazer parte da subjetividade daqueles que estão inseridos no sistema educacional, traduzindo-se em forma de relacionamentos e auto-percepção. Tendo em vista as dificuldades das crianças oriundas das classes subalternas (PATTO, 1984) para se inserirem e se manterem no contexto escolar, não raro, encontramos alunos (assim como seus familiares) que interpretam tal fracasso culpando-se, porque achama-se "burros", ou porque têm sua "cabeça oca". Em suma, uma questão que tem dimensões sociais passa a ser abordada e explicada no plano individual (MOYSÉS \& COLLARES, 1992).

\footnotetext{
1 Uma versão preliminar deste artigo foi apresentada no XXVI International Congress of Psychology, realizado em Montreal, no período de 16 a 21.08 .96 .

2 Departamento de Psicologia Social e Institucional da Universidade Estadual de Londrina
} 
O modelo liberal também marca a estruturação dos cursos de psicologia no Brasil a partir da década de 60 . Isto possibilitou o estabelecimento de um círculo vicioso entre o modelo de formação e a imagem social da profissão - o psicólogo é visto como um profissional atuando basicamente em consultórios, com a função de "curar" os indivíduos com problemas psicológicos 3 .

Uma pesquisa realizada em 1981 pelo Sindicato dos Psicólogos no Estado de São Paulo e pelo ConseIho Regional de Psicologia 6a Região (em 1981 o Conselho abrangia somente o Estado de São Paulo, atualmente abrange os Estados de São Paulo, Mato Grosso e Mato Grosso do Sul), junto às faculdades que ofereciam o curso de psicologia, revelou que o embasamento teórico da psicologia escolar ocorre tardiamente ( $7^{\circ}$ período, para os cursos semestrais), fato que parece interferir na visão que os alunos desenvolvem sobre a área como "área menor, de pouco peso".

Apesar desta pesquisa se referir aos anos 80, até este momento encontramos este mesmo viés nos cursos de formação de psicólogos. Tal situação reflete na manutenção da expectativa, por parte da sociedade e dos alunos que ingressam no curso, de que o psicólogo trabalha no consultório - "curando loucos".

Tal perspectiva tem um reflexo interessante junto às escolas. É comum identificarmos ali a percepção do psicólogo como uma espécie de "mágico", capaz de resolver todos os problemas que as crianças possam apresentar. Tal representação nos sugere duas hipóteses complementares: de um lado esta situação é uma tentativa de passar a responsabilidade da ação pedagógica para outra pessoa - e neste caso o psicólogo é bem vindo; por outro lado, na medida em que o psicólogo é visto como "mágico", o "cuidar de crianças" pode expressar um mecanismo de defesa - o que afasta a possibilidade de intervenção deste profissional junto a professores e direção.

Uma pesquisa realizada em 1994, junto às escolas que recebem atendimento da Área de Psicologia Escolar do Departamento de Psicologia Social e Institucional/UEL, revelou que as solicitações de trabaIho feitas por estas instituições estavam diretamente relacionadas ao "modelo clínico" referido anteriormente - esperava-se que as crianças com dificuldades fossem tratadas fora do contexto escolar e, após "a cura", fossem novamente inseridas nas salas de aula (COSTA, KUMATA \& SIQUEIRA, 1994) ${ }^{4}$.

Numa pesquisa recente realizada pelo CONSELHO REGIONAL DE PSICOLOGIA - 6ª REGIÃO (1995), constata-se que de um universo de 27.718 psicólogos que participaram da pesquisa, $40,75 \%$ atua em consultórios particulares, enquanto que 8,105 atua em escola. Nota-se, assim, que o consultório particular continua a ser o setor predominante de trabalho do psicólogo.

MACHADO et al (1993), numa investigação sobre a relação do psicólogo escolar com outros profissionais em escolas (públicas e particulares) da cidade de Ribeirão Preto, mostra-nos que a função mais exercida por estes profissionais no contexto escolar é a de mantenedor da disciplina escolar - entendida como uma "ação de suspensão de alunos quando necessário, conversa com pais tendo em vista a adaptação escolar dos alunos às normas da instituição" (p. 51).

Apesar das mudanças ocorridas na relação entre psicologia e educação ${ }^{5}$, até hoje o que se espera socialmente falando - do trabalho do psicólogo escolar é que ele resolva os problemas das crianças com dificuldades de aprendizagem, indisciplina, etc... através de um trabalho direto e exclusivo com elas (às vezes com seus familiares), sem relacionar esses problemas com o sistema educacional, as condições sociais, etc..., refletidos na escola.

Entendemos que a re-atualização do ideário liberal - hoje conhecido como neoliberalismo, assim como a formação acadêmica dos psicólogos, contribuem para a manutenção desta situação. Além disso, vale ressaltar que tal perspetiva de trabalho também está relacionada com a atuação deste profissional. Nesse sentido, lembra-nos CAETANO (1992): "é a prática profissional a responsável pela criação e manutenção da imagem de uma determinada profissão e dos serviços que ela pode oferecer ao público" (p. 45)

A partir da consideração de Caetano, vale ressaltar que as representações acerca do trabalho do psicólogo escolar é circunscrita por condições objetivas de nossa realidade, ou seja, por condições econômicas, sociais, políticas, etc... que, de uma certa forma, o localiza (assim com suas possibilidades de intervenção) no contexto social.

Desta forma, a discussão acerca do trabalho dos psicólogos escolares deve passar - necessariamente por uma compreensão dos fatores que possibilitaram a emergência das representações a respeito de seu trabalho - seja no contexto escolar, seja no contexto social em que está inserido. Conhecendo tais representações, assim como as condições que as engendraram, este profissional terá a possibilidade de promover as situações/relações que oportunizem a transformação das mesmas. Este será o mote para nossa discussão em seguida.

3 Em 1988 o Conselho Regional de Psicologia - 6" Região produziu um vídeo - "Psicologia, imagens e ações" - cujo objetivo foi o de documentar o que pensam profissionais e população sobre o que é psicologia. A partir de uma análise do filme podemos dizer que tal visão do psicólogo está muito presente em nossa população.

4 A mesma expectativa sobre o trabalho do psicólogo escolar é expressa por SOUZA (1992) em estágio realizado na Área de Psicologia Escolar do Curso de Psicologia da Faculdade de Ciências e Letras de Assis - UNESP. Ver também os dados colhidos pelo SINDICATO

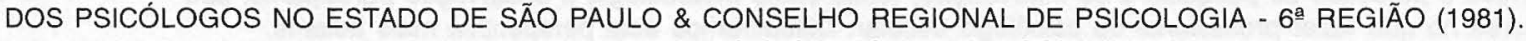

5 Para uma discussão acerca deste processo ver ALMEIDA \& GUZZO (1992) e COLL (1987). 


\section{OBSERVAÇÃO PARTICIPANTE E O QUE FAZER DO PSICÓLOGO ESCOLAR}

Antes de iniciarmos a discussão sobre a observação participante e o que esta metodologia oferece aos psicólogos escolares, convém esclarecermos a concepção de escola que norteia nosso trabalho, o que ajudará o leitor a situar melhor nossas propostas.

\section{Cotidiano escolar: o objeto para o psicólogo escolar}

Entendemos a escola como uma instituição sócio-cultural, organizada e pautada por valores, concepções e expectativas, perpassada por relações sociais na organização do trabalho e da produção. Nela os alunos, os professores, a direção, os pais e a comunidade são vistos como sujeitos históricos, culturais.

Na medida que abordamos a própria instituição escolar como um produto histórico cultural que age e interage numa trama de complexos processos sócioculturais, vislumbramos novas possibilidades para a construção de uma nova concepção de escola.

\section{Segundo EZPELETA \& ROCKWELL (1986)}

"A escola é, na teoria tradicional, uma instituição ou um aparelho do Estado. Tanto na versão positivista (Durkheim) como nas versões críticas (Althuser, Bourdieu), sua pertença ao Estado transforma-a automaticamente em representante univoca da vontade estatal. A escola tem uma história documentada, geralmente escrita a partir do poder estatal, a qual destaca sua existência homogênea. Coexiste, contudo, com esta história e existência documentada, outra história e existência, não documentada, através da qual a escola toma forma material, ganha vida. Nesta história, a determinação e presença estatal se entrecruza com as determinações e presença civis de variadas características. $A$ homogeneidade documentada decompõe-se em múltiplas realidades cotidianas. Nesta história não documentada, nesta dimensão cotidiana, os trabalhadores, os alunos e os pais se apropriam dos subsídios e das prescrições estatais e constroem a escola." "EZPELETA \& ROCKWELL, 1986, p. 12-3 - assinalamentos no original)

Sob esta ótica, a escola não é a mesma em todo o mundo capitalista, pois ela se realiza num mundo profundamente diverso e diferenciado. Olhando o movimento social a partir das situações e dos sujeitos que realizam anonimamente a escola, podemos dizer que a realidade de cada escola é uma construção social: a cons- trução de cada escola, mesmo circunscrita por um movimento histórico de longo alcance (como é o caso do capitalismo), é sempre uma versão local e particular. Dessa expressão local tomam forma internamente as correlações de forças, as condições trabalhistas, as formas de relação predominantes, as prioridades administrativas, as tradições docentes, que constituem a trama real em que se realiza a educação.

É uma trama em permanente construção que articula histórias locais - pessoais e coletivas -, diante das quais a vontade estatal abstrata pode ser assumida ou ignorada, mascarada ou recriada, em particular abrindo espaços variáveis a uma maior ou menor possibilidade hegemônica. Uma trama, finalmente, que é preciso conhecer, porque constitui, simultaneamente, 0 ponto de partida e o conteúdo do real em nossas alternativas tanto pedagógicas quanto políticas." (EZPELETA \& ROCKWELL, 1986, p. 11)

A observação participante permite ao psicólogo escolar inserido neste contexto "olhar" para o processo de apropriação de conhecimento dos vários segmentos que estão inseridos no ambiente escolar, o que significa analisar a existência cotidiana da esola como história acumulada; buscar, no seu presente, os elementos estatais e civis com as quais a escola se construiu. $\mathrm{Ou}$ seja, na observação da escola ele poderá averiguar o que é convergente, o que é divergente ou contraditório, nas diversas formas do existir da escola.

O cotidiano escolar, assim, passa a ser o espaço privilegiado para a pesquisa e para a intervenção do psicólogo escolar ${ }^{6}$, pois é aí onde se dá o encontro dos diversos segmentos que estão envolvidos com o dia-adia da escola, o que circunscreve o campo para a emergência das contradições que estão implícitas nas relações sociais que ali se desenvolvem ${ }^{7}$.

O cotidiano escolar, enfim, caracteriza-se como um campo de interseção entre sujeitos individuais que levam seus saberes específicos para a construção da escola. Nestes espaços incorporam-se e tornam-se significativos numerosos elementos não previstos na realidade, nas categorias tradicionais da realidade escolar. A realiade escolar aparece sempre mediada pela atividade cotidiana, pela apropriação, elaboração, refuncionalização ou repulsa que os sujeitos levam a cabo.

A partir do cotidiano escolar e através da observação participante, o psicólogo escolar terá acesso às representações sociais que medeiam as relações que se travam intra e extra instituição escolar. "As representações sociais... são as explicações e as afirma-

\footnotetext{
6 Entendemos que o processo de pesquisa e de intervenção, tendo como metodologia a observação participante, são

complementares no que fazer profissional do psicólogo escolar. Discutiremos esta perspectiva mais adiante.

7 KRAMER (1989) nos apresenta algumas destas contradições presentes no contexto de uma escola pública.
} 
ções que os indivíduos dão sobre sua realidade. É como assimila a estrutura social na qual integram suas experiências, valores, ou seja, é a relação que se estabelece entre o homem e o meio." (SALLES, 1990/1991, p. $15)^{8}$.

Representação social é, portanto, o conjunto de significados que os indivíduos estabelecem para a sua realidade, significados esses que são expressos pela linguagem. Tal perspectiva nos sugere que o psiquismo humano é produto da sociedade e, concomitantemente, as representações sociais são engendradas coletivamente pela sociedade. Nesse sentido, a partir de uma abordagem sócio-cultural do psiquismo humano ${ }^{9}$, entendemos que os significados são produzidos socialmente e se transformam através da atividade e pensamento dos indivíduos e, assim, individualizam-se, subjetivam-se.

Tendo em vista estas considerações, podemos dizer que, ao tomar o cotidiano escolar como espaço social de pesquisa/intervenção, o psicólogo escolar terá acesso as mediações que os indivíduos estabelecem para compreenderem sua realidade - as representações sociais - e assim, poderá desvelar os mecanismos utilizados (individual e coletivamente) na construção de sentidos para a realidade escolar. Dito de outra forma, o psicólogo escolar poderá desvelar os significados (convergentes ou contraditórios) que os agentes sociais envolvidos no processo educacional - pais, alunos, professores, direção, etc... - atribuem para a relação professor $x$ aluno, para o conhecimento, para o processo ensino/aprendizagem, para o processo de avaliação, etc..., além dos significados atribuídos ao próprio trabalho do psicólogo escolar.

Estas considerações levam-nos a indicar a observação participante como a metodologia mais adequada para o psicólogo escolar apreender, compreender e intervir no contexto escolar ${ }^{10}$. Por um lado, esta metodologia Ihe proporciona uma aproximação do cotidiano escolar e de suas representações sociais, resgatando sua dimensão histórica, sócio-cultural, seus processos. Por outro lado, permite-lhe intervir neste cotidiano, e nele trabalhar ao nível das representações sociais e propiciar a emergência de novas necessidades para os agentes que ali se "movimentam".

A observação participante se insere no conjunto das metodologias denominadas, no campo educacional, de "qualitativas"11 e, freqüentemente de etnográficas.
ANDRÉ (1992), avaliando a produção científica que se desenvolveu sob esta abordagem nos últimos dez anos avalia:

"O que se verifica, no entanto, é que a grande maioria envolve dados de campo, sistematizados em forma de descrições que acrescentam muito pouco ao que se sabe ou conhece ao nível do senso comum. É a empiria pela empiria. O autor parece satisfazer-se com o fato de coletar uma grande quantidade de dados e parece 'esperar' que esses dados por si produzam alguma teoria. Mas é evidente que sem um referencial de apoio que oriente o processo de reconstrução desses dados não há avanço teórico - fica-se na constatação do óbvio, na mesmice, na reprodução do senso comum." (ANDRÉ, 1992, p. 31/32)

A proposta que se coloca aqui vai na direção de superar tais limitações. Trata-se de ir para além do senso comum. Trata-se da tradição etnográfica cuja essência é identificada como "documentar a realidade nãodocumentada" (EZPELETA \& ROCKWELL, 1986, p. 15, n. 3). Ela se circunscreve, por um lado, pela utilização das categorias ${ }^{12}$ utilizadas pelas ciências sociais para a compreensão da realidade (como classe social, ideologia, poder, etc...) e, por outro, pela criação de novas categorias que são construídas/reconstruídas na relação pesquisador $x$ escola, pois

"... a heterogeneidade e a individualidade do cotidiano existem outras dimensões ordenadoras. Impõem forçosamente o reconhecimento de sujeitos que incorporam e objetivam, a seu modo, práticas e saberes dos quais apropriaram em diferentes momentos e contextos de vida, depositários que são de uma história acumulada durante séculos." (EZPELETA \& ROCKWELL, 1986, p. 28)

Através da observação participante, portanto, 0 psicólogo escolar poderá reconstruir os processos que ocorrem na vida diária da escola. Tal metodologia the permitirá integrar os vários momentos da escola e interpretar sua realidade cotidiana. Como tais processos se expressam por meio de elementos e situações diferentes que perpassam todos os âmbitos, com a metodologia acima indicada desvelar-se-á as tramas reais que se efetivam neste contexto e que se estruturam a partir de

\footnotetext{
Ver também o trabalho de BONFIN \& ALMEIDA, 1991/1992.

Para um aprofundamento desta perspectiva ver VYGOTSKY, 1991, 1991a e LEONTIEV, 1978.

10 O conceito de contexto que utilizamos para fazermos nossas proposições baseia-se na teoria psicológica histórico-cultural desenvolvida a partir das idéias de Vygotsky. Para tal teoria o contexto não se reduz ao entorno, ele expressa uma relação qualitativa onde os objetos e os sujeitos e o entorno se mesclam constituindo-se numa unidade de análise. Esta unidade compreende tanto os instrumentos materiais e simbólicos que permitem aos indivíduos adaptarem-se a realidade como a dimensão temporal, histórica na realidade humana que a configura. Para mais detalhes ver LACASA, 1993 e COLE, 1995.

11 Em 1983 aconteceu o Simpósio "A pesquisa qualitativa e o estudo da escola" onde foi discutida amplamente esta perspectiva de pesquisa em educação. Os trabalhos ali apresentados foram reproduzidos em Cadernos de Pesquisa, n. 49, $p$. 43-66.

12 Cabe salientar que a utilização de categorias oferecidas pelas ciências sociais, às vezes, limita o "olhar" do pesquisador sobre a escola, pois não the permite "enxergar" possibilidades outras de análises para tal realidade.
} 
pequenas histórias: espaços sociais onde se negocia e se reordena a continuidade das experiências e a atividade escolar. As contradições e incongruências aparentes que se encontram nos mais diversos espaços escolares (salas de aula, reuniões, na estrutura física da escola, etc...) adquirem sentido como resultado de mecanismos diferenciáveis de reprodução e de apropriação entre outros e mostram as diversas formas que a história - social e individual - está presente na vida cotidiana da escola.

A metodologia da observação participante, enfim, possibilita ao psicólogo escolar, inserido no contexto da escola, a "olhar" para as apropriações reais e potenciais que acontecem de baixo para cima: a partir dos sujeitos individuais que vivenciam diariamente a instituição. Além disso, ela cria a possibilidade de se construir um conhecimento que permite o estabelecimento de relações mais reais com os processos que se dão no interior das escolas.

Vale a pena resgatar, por um momento, algumas implicações da observação participante inerentes na relação psicólogo escolar x escola, considerando a dupla perspectiva de sua atividade: a de pesquisa e a intervenção. Para tal aprofundamento, faz-se necessário traçar algumas considerações sobre a observação participante tendo como ponto de partida a Antropologia.

\section{Observação Participante e a Antropologia}

A observação participante é uma metodologia elaborada principalmente no contexto da pesquisa antropológica. Trata-se de estabelecer uma adequada participação dos pesquisadores dentro dos grupos observados de modo a reduzir a estranheza recíproca. Os pesquisadores são levados a compartilhar os papéis e os hábitos dos grupos observados para estarem em condição de observar fatos, situações e comportamentos que não ocorreriam ou que seriam alterados na presença de estranhos. Foi MALINOWSKI (1978) quem sistematizou as regras metodológicas para a pesquisa antropológica: a idéia que caracterizava o método era a de que apenas através da imersão no cotidiano de uma outra cultura o antropólogo poderia chegar a compreendê-la.

Ou seja, um dos pressupostos da observação participante é o de que a convivência do investigador com a pessoa ou grupo estudado cria condições privilegiadas para que o processo de observação seja conduzido e dê acesso a uma compreensão que de outro modo não seria alcançável. Admite-se que a experiência direta do observador com a vida cotidiana do outro, seja ele indivíduo ou grupo, é capaz de revelar na sua significação mais profunda, ações, atitudes, episódios, etc.. que, de um ponto de vista exterior, poderiam permanecer obscurecidas ou até mesmo opacas.

Assim, o antropólogo deveria passar por um processo de transformação através do qual ele, idealmente, tornar-se-ia um nativo. No entanto, na medida em que essa experiência não é sistemática, o antropólogo deveria reelaborá-la, transformando-a numa descrição objetiva (científica?) da cultura. O resultado desta "transformação" consiste no texto etnográfico, onde o antropólogo apresenta uma re-elaboração de suas experiências.

O exercício desta metodologia trouxe para o centro da discussão epistemológica questões referentes a relação sujeito x objeto; a partir da qual podemos situar alguns desdobramentos.

Um dos problemas que se coloca para reflexão refere-se à relação entre o quanto se observa e o quanto se participa quando o pesquisador se encontra no campo. BRANDÃO (1984), com a perspectiva de superar tal questionamento, aponta uma certa orientação para a abordagem das relações que ali se estabelecem. Assim ele observa: "É necessário que o cientista e sua ciência seja, primeiro, um momento de compromisso e participação com o trabalho histórico e os projetos de luta do outro, a quem, mais do que conhecer para explicar, a pesquisa pretende compreender para servir". (BRANDÃO, 1984, p. 12)

Tal perspectiva supõe que os conhecimentos construídos na relação sujeito x objeto contribuem para a solução dos conflitos sociais emergentes nas relações sociais - luta contra a dominação e a opressão, contra o preconceito e as discriminações, etc... Assim, a relação do pesquisador junto ao campo de pesquisa é uma relação de implicação ${ }^{13}$ na vida da comunidade/ sociedade pesquisada, o que se traduz, para Brandão, em trabalho político e luta popular. Tal situação, na medida em que o outro se torna um companheiro de um compromisso, leva o pesquisador a repensar tanto sobre os destinos de sua pesquisa como também a respeito de sua posição pessoal.

"A relação de participação da prática científica no trabalho político das classes populares desafia o pesquisador a ver e compreender tais classes, seus sujeitos e seus mundos, tanto através de suas pessoas nominadas, quanto a partir de um trabalho social e político de 'classe', que constituindo a razão da prática, constitui igualmente a razão da pesquisa. Está inventada a pesquisa participante." (BRANDÃO, 1984, p. 13 assinalamentos no original) ${ }^{14}$

Um outro desdobramento de tal questão - a da relação sujeito $\mathrm{x}$ objeto - vem sendo discutida a partir

13 Para um aprofundamento de tal conceito, ver LOURAU, 1975; GUATTARI, 1987 e especialmente BARBIER, 1985.

14 Alguns têm se utilizado do termo pesquisa-ação para caracterizar tal abordagem. THIOLLENT (1984) estabelece as relações e as diferenças entre estas duas formas de se abordar a realidade. Ver também ARDOINO, 1993.

Ci. Sociais/Hum, 17, ก. 3, p. 266-273 
da emergência do paradigma hermenêutico no campo da Antropologia - que fundamenta a Antropologia Interpretativa a partir dos trabalhos de Clifford Geertz. Ao considerar que o trabalho do antropólogo é fazer etnografias e que estas são descrições densas ${ }^{15}$ que objetivam apreender uma cultura ${ }^{16}$; e ao considerar a etnografia como uma leitura - no sentido de 'construir uma leitura de' -, tal perspectiva coloca em pauta a postura do pesquisador no fazer antropológico, a qual se expressa no texto etnográfico, pois

"no estudo da cultura a análise penetra no próprio corpo do objeto, isto é, começamos com as nossas próprias interpretações do que pretendem nossos informantes, ou o que achamos que eles pretendem, e depois passamos a sistematizá-las ... (enfim) os textos antropológicos são eles mesmos interpretações e, na verdade, de segunda e terceira mão. Trata-se, portanto, de ficções; ficções no sentido de que são 'algo construído', 'algo modelado'. (GEERTZ, 1978:25-26 assinalamentos nossos)

O produto do trabalho do antropólogo - o texto etnográfico - é visto como o resultado da interação que se estabelece entre o pesquisador e seu objeto de estudo: uma interpretação que se elabora a partir do resgate da posição histórica do pesquisador na relação com seu objeto de estudo.

DaMatta, a partir destes pressupostos, considera que, em princípio, a Antropologia é uma ciências da "comutação e da mediação", pois

"Em antropologia é preciso recuperar esse lado extraordinário e estático das relações entre pesquisador/nativo. Se este é o lado menos rotineiro é o mais difícil de ser apanhado da situação antropológica, é certamente porque ele se constitui no aspecto mais humano de nossa rotina (...) Essa descoberta da Antrop clogia Social como matéria interpretativa segue, por outro lado, uma tendência ... que parece marcar sua passagem de uma ciência natural da sociedade, como queriam os empiricistas ingleses e americanos, para uma ciência interpretativa, destinada antes de tudo a confrontar subjetividades e tratar delas." (DAMATTA, 1978:11/12)

VELHO (1987), afirmando o caráter aproximativo do conhecimento devido a uma certa 'dose' de subjetividade do pesquisador, afirma
"A 'realidade' ... sempre é filtrada por determinado ponto de vista do observador, ela é percebida de maneira diferenciada. (...) não estou proclamando a falência do rigor científico no estudo das sociedades, mas a necessidade de percebê-lo enquanto objetividade relativa, mais ou menos ideológico e sempre interpretativo." (VELHO, 1987:129)

Estas questões levam-nos a pensar que a construção do objeto em Antropologia implica, simultaneamente, na construção do observador - o antropólogo. Tal possibilidade é assinalada por Tedlock ao apontar que o "domínio das Ciências Sociais caracteriza-se como um repertório de conhecimento e expectativas ou cultura comum, que foi compartilhado com os participantes e foi criado a partir da interação dos mesmos." (TEDLOCK, 1987:184 - assinalamento nosso)

O produto do trabalho de campo (o texto etnográfico), portanto, se constrói a partir da relação pesquisador $x$ pesquisado que ali se estabelece. Ena medida em que tal relação é um "encontro intersubjetivo", nela também estão envolvidos aspectos da construção da identidade tanto do antropólogo como de seu objeto de estudo, constituindo-se, portanto, faces de uma mesma moeda (MARTINS, 1995).

\section{Observação participante e pesquisa/intervenção do psicólogo escolar}

As considerações anteriores sobre a observação participante nos sugerem que esta maneira de abordar o cotidiano escolar cria uma relação de tensão para o psicólogo: de um lado, ele deve estabelecer, do ponto de vista analítico (ou seja, do ponto de vista epistemológico), um certo distanciamento do cotidiano escolar de tal modo que se possa conhecer seus interstícios. Por outro lado, deve buscar estabelecer uma relação de implicação junto aos agentes que estão envolvidos no processo educacional. Tal perspectiva é assim expressa por EZPELETA \& ROCKWELL (1986): "Na observação participante, as relações interpessoais entre pesquisador e sujeito, ali chamadas 'relações sociais', constituem as teorias; é a relação que determina o pensamento e não o contrário." (p. 83)

A intervenção do psicólogo, sob a perspectiva da observação participante, na medida em que tem como objeto o cotidiano escolar e as representações sociais que ali emergem, não deve se estruturar exclusivamente nas relações formais que se organizam dentro do

15 AZANHA (1992) vai propor para a pesquisa educacional a mesma proposição de Geertz: a elaboração de descrições densas.

16 Geertz define o objeto de estudo da Antropologia - a cultura - como essencialmente semiótica. Para ele o homem é um animal amarrado a teias de significados que ele mesmo teceu, [e assume] a cultura como sendo essas teias e a sua análise; portanto, não como uma ciência experimental em busca de leis, mas uma ciência interpretativa, à procura do significado". (GEERTZ, 1978:15) 
contexto escolar (reuniões, encontros no gabinete com alunos e professores, etc...). Ele deve considerar os espaços informais ("papos" nos corredores, hora do cafezinho, recreio dos alunos, etc...) como oportunidades tanto para conhecer (pesquisa) a realidade escolar como um espaço de intervenção junto ao universo das representações daqueles que ali se inserem e se expressam.

Nesse sentido, entendemos que a principal função do psicólogo dentro da escola é a de - a partir de seu cotidiano e de sua história - proporcionar situações coletivas onde se desvele os significados implícitos nas relações (sobre a escola, sobre o conhecimento, sobre o aluno, etc...), de tal forma que os envolvidos no processo dêem novos significados para as relações que ali estabelecem. Tal possibilidade, por sua vez, concretiza-se na medida em que o psicólogo cria oportunidades para que o coletivo da escola construa e crie novas necessidades para si, transforme as condições e os mecanismos de construção dos significados implícitos nas relações intra e extra escolares.

Tal perspectiva abre a possibilidade para a emergência das contradições que estão implícitas nas relações que se estruturam no contexto escolar, pois se oportuniza a expressão dos vários segmentos que compõem a estrutura social da escola. Isto nos faz pensar na força das contradições no engendramento das mudanças históricas e na capacidade do homem em promovê-las e superá-las.

Nesse sentido, ANDREAZI (1992) afirma:

"Onde encontrar marcas da identidade subjetiva simbolicamente evidenciadas? No espaço, nas coisas, nas regras, nos produtos das tarefas educativas, nas interações... Interessa perceber como as pessoas vêem e se vêem como elementos vinculados à Escola. Interessa para quê? Para uma compreensão da dinâmica institucional, poderes, resistências e percepções contraditórias de um mesmo Real tecido por sujeitos reais.
Que imagem se tem desta Escola? Que Escola ela pretende ser? Onde está, por onde transita o desejo dos que habitam este cotidiano? Da resposta a estas questões surge o perfil de uma instituição educacional que pode mirar-se, perceber-se como única, como história, recursos e possibilidades diferenciadas." (p. 94)

Iniciamos este trabalho assinalando que ainda se apresenta em nossa sociedade a idéia de que o psicólogo escolar é o profissional que trabalha com as "crianças problemas dentro da escola". Durante a nossa exposição, afirmamos que é a prática profissional que determina as representações sobre os profissionais de certas profissões. A partir das considerações acerca da inserção do psicólogo no cotidiano escolar através da observação participante, podemos vislumbrar algumas possibilidades de mudanças nas representações que se estruturam ao longo da história sobre a Psicologia Escolar. Nesse sentido, se o psicólogo abordar e intervir junto as representações sociais que medeiam suas relações com os envolvidos no ambiente escolar, desvelando os significados implícitos nestas representações - abordando-os a partir da história e do cotidiano escolar - abre-se a possibilidade para a emergência de novos significados tanto para sua presença no contexto escolar, como para o seu trabalho.

Trabalhar junto as pessoas, considerando-as enquanto sujeitos históricos de seus próprios processos ante os desafios do cotidiano escolar, permite-nos constatar que não existe uma única verdade acerca da realidade escolar, mas diferentes aproximações. Tais aproximações, possibilitadas por esse processo interativo (que não é fixo pela própria natureza da história) e pelas condições objetivas que a realidade social nos apresenta, deixa-nos como legado a idéia de que "viver e desenvolver-se implica em transformações contínuas que se realizam através da interação dos indivíduos entre si e entre os indivíduos e o meio no qual se inserem." (LIMA, 1990, p. 19)

MARTINS, J.B. Participative observation: a methodological approach to school psychology. Semina: Ci. Sociais/Humanas, Londrina, v. 17, n. 3, p. 266-273, Sep. 1996.

ABSTRACT: The purpose of this paper is to take the participative observation into consideration as an appropriate methodology to the work of scholar psychologists. We consider the school as a social construction prescribed through the representations of the social agents who participate in its day by day life. The participative observation permits the psychologists to research the structures of social relations and to give alternative ways to solve the problems in order to achieve the school goals. Therefore, the job of psychologists should be to get the social representations of school social segments in the sense to discover the contraditions that come up in the school relation routine.

KEY-WORDS: School Psychology - Participative Observation - Research Methodology - Quotidian 


\section{REFERÊNCIAS BIBLIOGRÁFICAS}

"A pesquisa qualitativa e o estudo da escola" (Simpósio). Cadernos de pesquisa. São Paulo, n. 49, p. 43-66, 1984

ALMEIDA, L.S. \& GUZZO, R.S.L. A relação psicologia e educação. Estudos de Psicologia. Campinas, v. 9, n. 3, p. $117-131,1992$

ANDALÓ, C.S. de L. O papel do psicólogo escolar. Psicologia, Ciência e Profissão. Brasília. CFP. Ano IV, n. 1, p. 43-46, 1984.

ANDRÉ, M.E.D.A. Cotidiano escolar e práticas sóciopedagógicas. Em Aberto. Brasília. Ano 11, n. 53, p. 29-38, 1992.

ANDREAZI, L.C. Uma história do olhar e do fazer do psicólogo na escola. In: CAMPOS, Florianita C. B. (org.). Psicologia e saúde: repensando práticas. S. Paulo: Hucitec, p. 65-84, 1992.

ARDOINO, J. Editorial: De uma ambigüidade própria a pesquisa-ação as confusões mantidas pelas práticas de intervenção. Revista Brasileira de Estudos Pedagógicos Brasília. v. 74, n. 178, p. $701-720$, set/dez. 1993.

AZANHA, J.M.P. Uma idéia de pesquisa educacional. São Paulo: EDUSP: FAPESP, 1992

BARBIER, R. A pesquisa-ação na instituição educativa. Rio de Janeiro: Jorge Zahar, 1985.

BONFIN, Z.A.C. \& ALMEIDA, S.F.C. de. Representação social: conceituação, dimensão e funções. Revista de Psicologia. Fortaleza; v. 9, n. 1/2, p. 75-89, 1991/1992

BRANDÃO, C.R. Participar-pesquisar. In: BRANDÃO, Carlos Rodrigues (org.). Repensando a pesquisa participante. São Paulo: Brasiliense, 1984, p. 7-14

CAETANO, M.O.A. A construção de representação social: a representação de pais e alunos sobre a atuação do psicólogo na escolar. PUC/SP. Dissertação de Mestrado, 1992.

COLE, M. Socio-cultural-historical psycholog: some general remarks and a proposal for a new kind of cultural-genetic methodolog. In: WERTSCH, James V.; RIO, Pablo Del \& Alvarez, Amelia. Sociocultural studies of mind. Cambridge: Cambridge University Press, 1995, p. 187-214.

COLL, C. As contribuições da psicologia para a educação: teoria genética e aprendizagem escolar. In: LEITE, Luci Banks (org.). Piaget e a Escola de Genebra. São Paulo: Cortez, 1987, p. 164-197.

CONSELHO REGIONAL DE PSICOLOGIA - 6 $6^{\mathrm{a}}$ REGIÃO. Psicologia: formação, atuação profissional e mercado de trabalho - Estatísticas 1995. São Paulo: CRP/06, 1995.

COSTA, A.C.; KUMATA, L.Y. \& SIQUEIRA, S. de L. Esclarecimento do papel do psicólogo em instituição escolar e levantamento nas escolas das facilidades/dificuldades encontradas pelos estagiários. Relatório de Pesquisa. Londrina: Dep. Psicologia Social e Institucional/UEL. 1994, mimeo.

DAMATTA, R. O oficio de etnólogo ou como ter anthropological blues. Boletim do Museu Nacional - Nova Série. Rio de Janeiro. n. 27 , maio/1978.

EZPELETA, J. \& ROCKWELL, E. Pesquisa participante. São Paulo: Cortez: Autores Associados, 1986.

FIGUEIREDO, L.C.M. Matrizes do pensamento psicológico. Petrópolis: Vozes, 1991

FIGUEIREDO, L.C.M. Sob o signo da multiplicidade. Estudos de Psicologia. Campinas. v. 10, n. 1, p. 11-18, 1993

GEERTZ, C. A interpretação das culturas. Rio de Janeiro: Zahar, 1978

GUATTARI, F. Revolução molecular: pulsações políticas do desejo. 3 ed., São Paulo: Brasiliense, 1987.

KRAMER, S. Melhoria da qualidade do ensino: o desafio da formação de professores em serviço. Revista Brasileira de Estudos Pedagógicos. Brasilia. v. 79, n. 165, p. 189-207, maio/ago 1989.

LACASA, P. Aprender en la escuela, aprender en la calle. Madrid: Visor, 12993

LEONTIEV, A.N. O desenvolvimento do psiquismo. Lisboa: Horizonte, 1978

LIMA, E.C. de S. Algumas questões sobre o desenvolvimento do ser humano e a aquisição de conhecimentos na escola. In: PARANÁ. SECRETARIA DE EDUCACÃO DO ESTADO.

Currículo Básico para a Escola Pública do Estado do Paraná. Curitiba: SEED, p. 19-23, 1990.

LOURAU, R. A análise institucional. Petrópolis: Vozes, 1975.

MACHADO, V.L.S. et al. Psicólogo escolar, orientador pedagógico e assistente pedagógico na escola: um trabalho em cooperação? Paidéia. Rib. Preto/USP. n. 4, p. 45-63, 1993

MALINOWSKI, B. Argonautas do Pacífico Ocidental. 2 ed., São Paulo: Abril Cultural, 1978.

MARTINS, J.B. Marolas antropológicas: identidades em mudança na Praia do Santinho. Florianópolis, UFSC, Dissertação de Mestrado, 1995.

MOYSÉS, M.A.A. \& COLLARES, C.A.L. A história não contada dos distúrbios de aprendizagem. Cadernos CEDES 28: O sucesso escolar: um desafio pedagógico. Campinas: Papirus, pag. 31-47, 1992.

PATTO, M.H.S. Psicologia e ideologia: uma introdução crítica a psicologia escolar. São Paulo: T.A. Queiroz, 1984.

SALLES, L.M.F. Representação social e cotidiano. Didática São Paulo. v. 26/27, p. 11-20, 1990/1991.

SINDICATO DOS PSICÓLOGOS NO ESTADO DE SÃO PAULO \& CONSELHO REGIONAL DE PSICOLOGIA - 6 REGIÃO. Anais do I Encontro de Psicólogos da Área de Educação. São Paulo: do Autor, 1981.

SOUZA, M. de. Relatório (a bordo) de meia-viagem: uma experiência (em trânsito) em psicologia escolar. Vertentes. Assis. n. 2, p. 93-105, 1992

TEDLOCK, D. A tradição analógica e o surgimento de uma antropologia diabólica. Anuário de Antropologia/85, 1988

THIOLLENT, M. Notas para o debate sobre a pesquisa-ação. In: BRANDÃO, Carlos Rodrigues (org.) Repensando a pesquisa participante. São Paulo: Brasiliense, 1984, p. 82-103.

VELHO, G. Observando o familiar. In: VELHO, G Individualismo e cultura: notas para uma antropologia da sociedades contemporânea. 2. ed., Rio de Janeiro: Jorge Zahar, 1987, p. 121-132.

VYGOTSKY, L.S. Pensamento e linguagem. 3. ed., São Paulo: Martins Fontes, 1991.

VYGOTSKY, L.S. A formação social da mente. 3. ed., São Paulo: Martins Fontes, 1991a. 